Jurnal Keperawatan Profesional (JKP)

Volume 7, Nomor 1 Februari 2019

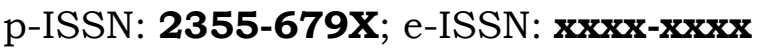

https://ejournal.unuja.ac.id/index.php/jkp/index

\title{
Hubungan Pola Asuh Orang Tua dalam Menstimulasi Perkembangan Motorik Kasar dan Halus Usia Pra Sekolah
}

Zainal Munir ${ }^{1}$, Yulisyowati ${ }^{2}$, Helpy Virana3

1. Universitas Nurul Jadid, Probolinggo

2. STIKES Bahrul Ulum Jombang

3. Universitas Nurul Jadid, Probolinggo

\section{Abstract}

At this stage of growth and development of children pre- school age 3-4 years, children begin to master a variety of physical skills and courage. However, there are still come pre school age children are to afraid of being in a foreign environment at school. If that happens then the pre school children have delays in development. Child development is influence by the pattern of care applied by the parents. Authoritative parenting strongly influence the high level of courage and skill of children. The study aims to determine the relationship of parenting the parent to stimulate the development of groos motor and fine motor skills in children. Research methods and correlational design using cross sectional approach by using purposive sampling techniqus sampling. The population of this study were parents with pre school age children 3-4 years in early childhood AL-Firdaus Bahrul 'Ulum Tambakberas Jombang, which amount to 32 people with a large sample of 22 people. Method of data collection use questionnaires and observation sheets DDST (Denver Development Screening Test), and then data is analyzed by Chi-Square test. The result of correlation analysis Chi-Square majority of respondents found that authoritative parenting implement as 
Jurnal Keperawatan Profesional (JKP)

Volume 7, Nomor 1 Februari 2019

p-ISSN: 2355-679X; e-ISSN: $\mathbf{x x x x - x x x x x}$

https://ejournal.unuja.ac.id/index.php/jkp/index

many as 20 people (90,9\%) with development of gross motor that delay. Respondent who apply the authoritative parenting style with development of fine motor skills that normal . And indulgent parenting style with development of fine motor skills that delay with Asymp. Sig $\rho$ $=0.000$, which means there is a relationship between the pattern of care in stimulating the development of gross motor and fine motor skills of children. From this research it can be concluded that authoritative parenting pattern can be applied to parents of pre school children aged 3-4 years so that children growth and develop well in early childhood Bahrul 'Ulum ALFirdaus Tambakberas Jombang.

Keywords: Parenting pattern, gwoth and development, Denver Development Skrining Test

\section{Abstrak}

Pada tahap pertumbuhan dan perkembangan anak usia pra sekolah 3-4 tahun, anak mulai menguasai berbagai ketrampilan fisik dan keberanian. Namun, masih ada sebagian anak usia pra sekolah terlalu takut berada di lingkungan asing ataupun disekolah. Apabila hal itu terjadi maka anak pra sekolah tersebut memiliki keterhambatan dalam perkembangan. Perkembangan anak ini dipengaruhi dari pola asuh yang diterapkan oleh orang tua. Pola asuh authoritative sangat mempengaruhi tingginya tingkat keberanian dan keterampilan anak. Penelitian bertujuan untuk mengetahui hubungan pola asuh orang tua dalam menstimulasi perkembangan motorik kasar dan motorik halus pada anak. Metode 
Jurnal Keperawatan Profesional (JKP)

Volume 7, Nomor 1 Februari 2019

p-ISSN: 2355-679X; e-ISSN: $\mathbf{x x x x - x x x x x}$

https://ejournal.unuja.ac.id/index.php/jkp/index

penelitian dengan desain korelasional dan mengunakan pendekatan Cross Sectional dengan menggunakan tekhnik sampling Purposive Sampling. Populasi pada penelitian ini adalah orang tua yang memiliki anak usia pra sekolah 3-4 tahun di PAUD AL-Firdaus Bahrul 'Ulum Tambakberas Jombang, yang berjumlah 32 orang dengan besar sampel 22 orang. Cara pengambilan data dengan kuesioner dan observasi lembar DDST (Denver Development Skrining Test), kemudian dianalisa data dengan uji Chi-Square. Hasil analisa korelasi uji Chi - Square didapatkan sebagian responden yang menerapkan pola asuh authoritative sebanyak 20 orang $(90,9 \%)$ dengan perkembangan motorik kasar yang normal. Sedangkan pola asuh indulgent sebanyak 2 orang $(9,1 \%)$ dengan perkembangan motorik kasarnya delay. Responden yang menerapkan pola asuh authoritative dengan perkembangan motorik halus normal. Dan pola asuh indulgent dengan perkembangan delay dengan Asymp.Sig $\rho=$ 0,000, yang artinya ada hubungan antara pola asuh dalam menstimulasi perkembangan motorik kasar dan motorik halus anak. Dari penelitian ini dapat disimpulkan bahwa pola asuh orang tua authoritative dapat diterapkan pada orang tua terhadap anak usia pra sekolah usia 3-4 tahun agar anak tumbuh dan berkembang dengan baik di PAUD AL-Firdaus Bahrul 'Ulum Tambakberas Jombang.

Kata Kunci: Pola asuh, stimulasi, pertumbuhan dan perkembangan, tes DDST 
Jurnal Keperawatan Profesional (JKP)

Volume 7, Nomor 1 Februari 2019

p-ISSN: 2355-679X; e-ISSN: $\mathbf{x x x x - x x x x}$

\section{Pendahuluan}

Pertumbuhan dan perkembangan mengalami peningkatan yang pesat pada usia dini, yaitu dari 0 sampai 5 tahun. Masa ini sering juga disebut sebagai fase "Golden Age". Golden age merupakan masa yang sangat penting untuk memperhatikan tumbuh kembang anak secara cermat agar sedini mungkin dapat terdeteksi apabila terjadi kelainan. Selain itu, penanganan kelainan yang sesuai pada masa golden age dapat meminimalisir kelainan pertumbuhan dan perkembangan anak sehingga kelaianan yang bersifat permanen dapat dicegah (Soejiningsih, 2003).

Sesungguhnya

pendidikan yang utama dan pertama bagi anak usia dini berada di rumah bersama orang tua (Ayah dan Ibu). Indikatornya adalah: (1) orang tua merupakan orang yang paling bertanggung jawab terhadap perkembangan anakanaknya, (2) orang tua merupakan orang yang pertama berinteraksi dengan anakanaknya sebelum mereka berinteraksi dengan orang lain,
(3) lingkungan keluarga merupakan lingkungan terdekat (micro system) yang sangat berpengaruh terhadap kepribadian anak, dan (4) waktu yang dimiliki oleh anak lebih banyak dihabiskan di rumah bersama orang tua. Dengan demikian pemberian asah, asih dan asuh kepada anak usia dini menjadi tanggung jawab utama bagi orang tua. Orang tua dan orangorang yang terdekat dengan kehidupan anak, memberi pengaruh yang sangat besar terhadap pertumbuhan dan perkembangan anak. Di PAUD (Pendidikan Anak Usia Dini) AL-Firdaus Bahrul 'Ulum Tambakberas Jombang, tidak satu pun orang tua yang tidak menginginkan buah hatinya tumbuh menjadi manusia dewasa yang tidak cerdas dan mandiri. Padahal orang tua sekarang sibuk dengan bekerja, akan tetapi anak pun membutuhkan lebih banyak perhatian orang tua. Demikian juga halnya dengan perkembangan motorik anak akan lebih teroptimalkan jika lingkungan tempat tumbuh kembang anak mendukung mereka untuk bergerak bebas. 
Kecemasan pada pasien sebelum dilakukan tindakan operasi juga bisa disebabkan karena kurang informasi tentang prosedur tindakan dan komunikasi antara perawat dengan pasien yang kurang efektif.

Orang tua adalah orang pertama dan utama bagi anak. Dalam keluarga anak mendapat rangsangan, hambatan dan pengaruh yang pertama-tama dalam pertumbuhan dan perkembangannya, baik perkembangan biologis maupun perkembangan jiwanya. Jika anak kurang mendapat stimulasi dari orang tua maka akan berdampak menurunnya perkembangan motorik sebagian besar anak akan mengalami gangguan belajar, misalnya orang tua yang memberikan pola asuh secara otoriter, neglectful maupun indulgent maka akan berdampak buruk bagi perkembangan anak, anak akan merasa tertekan, kurang kreatifitasnya serta anak jadi tidak belajar mengontrol diri. Sedangkan pola asuh yang authoritative akan berdampak positif bagi perkembangan anak, anak akan tumbuh lebih dewasa dan memiliki rasa percaya diri yang terpupuk sejak kecil. Orang tua secara mendasar mempunyai peran dan tanggung jawab yang sangat mendasar dalam menentukan kemajuan bangsa dan negaranya. Hal tersebut sangat bergantung kepada bagaimana orang tua dalam memberi pengasuhan kepada anak-anak mereka.

Oleh karena itu, orang tua harus mengenali dan mendeteksi sejak kecil kelebihan dan kekurangan perkembangan motorik pada anak. Jika terdapat kekurangan dalam perkembangan motorik lainnya harus diberikan latihan sejak dini agar keterlambatan tersebut dapat diminimalkan. Hal ini dapat dilakukan dengan dorongan kegiatan khusus untuk menciptakan perkembangan anak yang lebih optimal. Perkembangan anak usia pra sekolah (3-4 tahun) di PAUD AL-Firdaus Bahrul 'Ulum Tambakberas 
Jombang ada yang mengalami keterlambatan dalam tumbuh kembang, misalnya: ada anak yang belum dapat menulis beberapa huruf, memotong bentuk-bentuk sederhana, dan melompat dengan satu kaki.

\section{Metode}

Penelitian

ini menggunakan cross sectional penelitian dimana variabelvariabel yang termasuk faktor resiko dan variabel-variabelvariabel yang termasuk efek diobservasi sekaligus pada waktu yang sama dan menggunakan studi korelasi merupakan penelitian hubungan antara dua variabel pada situasi atau sekelompok subyek, penentuan sampel penelitian memberikan beberapa kriterian baik inklusi dan ekslusi jumlah Populasi 57 Orang sehingga setelah ditentukan dengan kriteria yang telah didapatkan maka didapatkan sampel pada penelitian ini sebanyak 22 Orang. Sampel yang telah ditentukan dengan melihat kriteria yang telah ditetapkan oleh penelitian menjadikan keterwakilan dari jumlah populasi. Penelitian ini dilakukan di PAUD ALFirdaus Bahrul 'Ulum Tambakberas Jombang. Hasil Penelitian

1. Data Umum

a. Karakteristik Orangtua (Ayah ) berdasarkan Umur

Tabel 1 Distribusi berdasarkan Umur Orangtua (Ayah)

\begin{tabular}{cccc}
\hline No & Umur & $\mathrm{F}$ & $\%$ \\
\hline 1 & $15-24$ & 0 & 0 \\
2 & $25-34$ & 4 & 18,2 \\
\hline 3 & $>35$ & 18 & 81,8 \\
\hline & Total & $\mathbf{2 2}$ & $\mathbf{1 0 0}$
\end{tabular}

Berdasarkan hasil penelitian pada tabel 1 di atas, didapatkan sebagian besar umur Ayah yaitu 15-24 tahun sebanyak 0 orang (0\%), 25-34 tahun sebanyak 4 orang $(18,2 \%)$ dan umur >35tahun sebanyak 18 orang $(81,8 \%)$.

b. Karakteristik Orangtua (Ayah) berdasarkan Pendidikan

Tabel 2

Distribusi

berdasarkan

Pendidikan

Orangtua (Ayah)

\begin{tabular}{cccc}
\hline No & Pendidikan & F & $\%$ \\
\hline 1 & SD & 0 & 0 \\
2 & SMP & 2 & 9,1 \\
3 & SMA & 8 & 36,4 \\
\hline 4 & PT & 12 & 54,5 \\
\hline & Total & $\mathbf{2 2}$ & $\mathbf{1 0 0}$ \\
\hline & & &
\end{tabular}


Berdasarkan hasil penelitian pada tabel 2, didapatkan sebagian besar pendidikan ayah yaitu SMP sebanyak 2 orang $(9,1 \%)$ dan PT sebanyak 12 orang $(54,5 \%)$.

\section{Data Khusus}

a. Karakteristik pola asuh orang tua wali murid anak usia pra sekolah (3-4 tahun) di PAUD ALFirdaus Bahrul 'Ulum Tambakberas Jombang.

Tabel 3 Distribusi berdasarkan pola asuh orang tua wali murid anak usia pra sekolah (3-4 tahun)

\begin{tabular}{ccc}
\hline $\begin{array}{c}\text { Pola Asuh Orang } \\
\text { Tua }\end{array}$ & $\mathrm{F}$ & $(\%)$ \\
\hline Authoritative & 20 & 90,9 \\
Otoriter & 0 & 0 \\
Neglectful & 0 & 0 \\
Indulgent & 2 & 9,1 \\
\hline$\sum$ & $\mathbf{2 2}$ & $\mathbf{1 0 0}$
\end{tabular}

Berdasarkan data yang
diperoleh pada tabel 3 menunjukkan bahwa orang tua yang menerapkan pola asuh Authoritative sebanyak 20 orang $(90,9 \%)$ dan pola asuh indulgent sebanyak 2 orang $(9,1 \%)$.

b.Perkembangan motorik kasar
Tabel 4 Distribusi

perkembangan motorik kasar anak usia pra sekolah (3-4 tahun) di PAUD AL-Firdaus Bahrul 'Ulum Tambakberas Jombang

\begin{tabular}{ccc}
\hline $\begin{array}{c}\text { Perkembangan } \\
\text { motorik kasar }\end{array}$ & F & $(\boldsymbol{\%})$ \\
\hline Lebih/ advanced & 6 & 27,3 \\
Normal & 14 & 63,7 \\
Caution & 0 & 0 \\
Delay & 2 & 9,1 \\
No opportunity & 0 & 0 \\
\hline$\sum$ & $\mathbf{2 2}$ & $\mathbf{1 0 0}$
\end{tabular}

Berdasarkan data yang diperoleh pada tabel 4 didapatkan bahwa perkembangan motorik kasar anak usia pra sekolah 3-4 tahun di PAUD AL-Firdaus Bahrul 'Ulum Tambakberas Jombang sebagian responden perkembangannya normal sebanyak 8 orang $(63,7 \%)$ dan delay sebanyak 2 orang $(9,1 \%)$

c. Perkembangan motorik halus.

Tabel 5 Distribusi

perkembangan motorik halus anak usia pra sekolah (3-4 tahun) di PAUD AL-Firdaus Bahrul 'Ulum Tambakberas Jombang 


\section{Zainal Munir: Menstimulasi Perkembangan}

\begin{tabular}{ccc}
\hline $\begin{array}{c}\text { Perkembangan } \\
\text { motorik halus }\end{array}$ & $\mathrm{F}$ & $(\%)$ \\
\hline Lebih/ advanced & 4 & 18,2 \\
Normal & 16 & 72,7 \\
Caution & 0 & 0 \\
Delay & 2 & 9,1 \\
No opportunity & 0 & 0 \\
\hline$\sum$ & $\mathbf{2 2}$ & $\mathbf{1 0 0}$
\end{tabular}

$\overline{\text { Berdasarkan data yang diperoleh }}$ pada tabel 5 didapatkan bahwa perkembangan motorik halus usia anak pra sekolah di PAUD AL-Firdaus Bahrul 'Ulum Tambakberas Jombang, sebagian responden perkembangan normal sebanyak 16 orang $(72,7 \%)$ dan delay sebanyak 2 orang $(9,1 \%)$.
d. Hubungan pola asuh orang tua dalam menstimulasi
perkembangan motorik kasar

Tabel 6 hubungan pola asuh orang tua dalam menstimulasi perkembangan motorik kasar anak usia pra sekolah (3-4 tahun) di PAUD AL-Firdaus Bahrul 'Ulum Tambakberas Jombang

\begin{tabular}{cccccc}
\hline $\begin{array}{c}\text { Pola } \\
\text { asuh } \\
\text { oran } \\
\mathrm{g}\end{array}$ & $\begin{array}{c}\text { adva } \\
\text { nced }\end{array}$ & Normal & Caution & Delay & Total \\
tua & & & & & \\
\hline Aut & 6 & 14 & 0 & 0 & 20 \\
hori & 40,0 & $60,0 \%$ & $0 \%$ & $0 \%$ & $100 \%$ \\
tativ & $\%$ & & & & \\
$\mathrm{e}$ & & 0 & 0 & 2 & 2 \\
$\begin{array}{c}\text { Indu } \\
\text { lgen }\end{array}$ & $0 \%$ & $0 \%$ & $0 \%$ & $100 \%$ & $100 \%$ \\
$\mathrm{t}$ & \multicolumn{7}{c}{ Total } & & 22 \\
\hline \multicolumn{7}{c}{} \\
\hline
\end{tabular}

Berdasarkan data yang diperoleh pada tabel 6 diketahui hubungan pola asuh orang tua dalam menstimulasi perkembangan motorik kasar anak usia pra sekolah 3-4 tahun di PAUD ALFirdaus Bahrul 'Ulum Tambakberas Jombang sebagian responden yang menerapkan pola asuh authoritative dengan perkembangan motorik kasar yang normal 14 orang $(60,0 \%)$, lebih/ advanced sebanyak 6 orang $(40,0 \%)$ dari 20 responden. Sedangkan sebagian responden yang menerapkan pola asuh indulgent didapat dengan perkembangan motorik kasar delay sebanyak 2 orang (100\%) dari 2 responden.

Berdasarkan hasil uji Chi square didapat hasil $\rho$ value signifikan $0,000<0,05$ yang artinya Ho di tolak berarti ada hubungan antara pola asuh orang tua dalam menstimulasi perkembangan motorik kasar. 
e. Hubungan pola asuh orang tua dalam menstimulasi perkembangan motorik halus.

Tabel 7 Distribusi hubungan pola asuh orang tua dalam menstimulasi perkembangan motorik halus anak usia pra sekolah (3-4 tahun) di PAUD AL-Firdaus Bahrul 'Ulum Tambakberas Jombang

\begin{tabular}{cccccc}
\hline $\begin{array}{c}\text { Pola asuh } \\
\text { orang tua }\end{array}$ & \multicolumn{4}{c}{ Perkembangan motorik halus } & \multirow{2}{*}{ Total } \\
\cline { 2 - 4 } & $\begin{array}{c}\text { advanc } \\
\text { ed }\end{array}$ & $\begin{array}{c}\text { Nor } \\
\text { mal }\end{array}$ & $\begin{array}{c}\text { Cautio } \\
\mathrm{n}\end{array}$ & Delay & \\
& & & & & \\
Authorita & 4 & 16 & 0 & 0 & 20 \\
tive & $20,0 \%$ & 80,0 & $0 \%$ & $0 \%$ & $100 \%$ \\
Indulgent & 0 & 0 & 0 & 2 & 2 \\
& $0 \%$ & $0 \%$ & $0 \%$ & $100 \%$ & $100 \%$ \\
\hline & & Total & & & 22 \\
& & & & & $100 \%$
\end{tabular}

Dari tabel 7 diketahui hubungan pola asuh orang tua dalam menstimulasi perkembangan motorik kasar anak usia pra sekolah 3-4 tahun di PAUD ALFirdaus Bahrul 'Ulum Tambakberas Jombang sebagian responden yang menerapkan pola asuh authoritative dengan perkembangan motorik halus yang advanced sebanyak 4 orang (20\%), normal 16 orang $(80,0 \%)$ dari 20 responden. Sedangkan orang tua yang menerapkan pola asuh indulgent dengan perkembangan motorik halus yaitu delay sebanyak 2 orang $(100 \%)$ dari 2 responden.

Berdasarkan hasil uji Chi square didapat hasil $\rho$ value signifikan $0,000<0,05$ yang artinya Ho di tolak, berarti ada hubungan antara pola asuh orang tua dalam menstimulasi perkembangan motorik halus.

\section{Pembahasan}

1. Pola asuh orang tua

Dari hasil yang telah ditabulasi didapatkan lebih dari sebagianresponden menerapkan pola asuh authoritative sebanyak 20 orang $(90,9 \%)$ dan yang menerapkan pola asuh indulgent sebanyak 2 orang $(9,1 \%)$.

Menurut Dinarti, (2010: 18) pola asuh orang tua yang baik untuk pembentukan kepribadian anak adalah pola asuh yang memprioritaskan kepentingan anak, akan tetapi orang tua juga mengawasi dan mengendalikan anak dengan pola pengasuhan seperti ini, akan terbentuk karakteristik anak yang dapat mengontrol diri, mandiri, mempunyai hubungan baik dengan teman, mampu menghadapi stres dan mempunyai minat terhadap hal-hal baru. Secara sederhana dapat dikatakan bahwa pola asuh merupakan proses interaksi antara anak 
dengan orang tua dalam pembelajaran dan pendidikan yang nantinya sangat bermanfaat bagi aspek pertumbuhan dan perkembangan anak.

Dengan demikian pengasuhan yang diberikan oleh orang tua lebih mengutamakan kasih sayang, kebersamaan, musyawarah, saling pengertian dan penuh keterbukaan. Pola asuh ini dipengaruhi oleh faktorfaktor diantaranya faktor usia, pendidikan dan pengalaman dalam mengasuh anak. Semakin matangnya usia, pendidikan dan pengalaman orang tua dalam mengasuh anak maka akan semakin baik juga pengalaman orang tua dalam mendidik dan melatih anak. Pola asuh orang tua yang baik untuk membentuk anak dan melatih perkembangan anak ialah dengan pola asuh authoritative, karena dengan pola asuh ini anak akan mempunyai keinginan untuk mencoba dan berprestasi serta bisa dijadikan pilihan bagi orang tua dalam mendidik dan mengasuh anak agar berkembang dengan baik dan optimal.

Dalam mengasuh anak hendaknya orang tua bersifat arif dan bijaksana dalam arti mampu memberi pengasuhan yang sesuai dengan apa yang sedang dilakukan anak dan harapan orang tua.

2. Perkembangan motorik kasar Setelah dilakukan tabulasi dari hasil observasi didapat sebagian besar responden dengan perkembangan motorik kasarnya dikatakan lebih/ advanced sebanyak 6 orang $(27,3 \%)$, normal sebanyak 14 orang $(63,7 \%)$ dan delay sebanyak 2 orang $(9,1 \%)$.

Motorik kasar adalah gerakan tubuh yang menggunakan otot-otot besar atau sebagian besar atau seluruh anggota tubuh yang dipengaruhi oleh kematangan anak itu sendiri. Contohnya kemampuan duduk, menendang, berlari, naik-turun tangga dan sebagainya. Menurut Hidayat (2007), perkembangan motorik kasar menurut lembar observasi DDST anak usia 3-4 tahun diantaranya : berdiri pada 1 kaki 10 detik/ 2 dari 3 , menangkap bola 2 dari 3 , berjalan pada tumit jari kaki 2 dari 3, lompat pada 1 kaki, berdiri pada 1 kaki 5 detik/ 2 dari 3, lompatan lebar dan berdiri pada 1 kaki selama 1 detik. Dari hasil observasi DDST yang dilakukan peneliti, perkembangan motorik kasar anak yang dicapai normal 
diantaranya berjalan dengan tumit kaki, lompat dengan 1 kaki dan menangkap bola, sedangkan yang masih belum dicapai anak diantanya seperti berdiri dengan 1 kaki karena anak tersebut masih belajar berdiri dengan 1 kaki selama 5-10 detik dengan berpegangan pada tembok bahkan dibantu oleh orang tuanya. Dengan demikian anak-anak lebih dilatih lagi dalam perkembangan motorik kasarnya agar dapat melatih otot-otot besar pada anak untuk bisa berkembang lebih baik. Perkembangan motorik kasar ini dipengaruhi oleh kematangan anak itu sendiri. Anak yang mencapai perkembangan motorik kasar yang normal bahkan lebih/ advanced maka anak itu memiliki keyakinan dan percaya diri bahwa dirinya pasti bisa melakukan hal tersebut. Sebaliknya jika anak yang perkembangan motorik kasarnya mengalami keterlambatan atau delay dan caution karena faktor anak tersebut yang merasa takut dan tidak yakin dengan apa yang dilakukan. Perkembangan motorik ini juga dipengaruhi oleh beberapa faktor yang diantaranya ialah faktor lingkungan, faktor gizi, peran aktif orang tua dan pola pengasuhan. Faktor-faktor tersebut sangat berpengaruh dalam menstimulasi perkembangan motorik anak karena dengan gizi yang baik, lingkungan yang merangsang perkembangan anak, peran aktif orang tua dan pola pengasuhan yang tepat akan membuat perkembangan anak menjadi lebih sempurna.

Gerakan tubuh anak pada aspek ini perlu dilatih agar dapat berkembang dengan baik dengan melakukan dorongan kegaitan khusus seperti melatih anak untuk belajar berdiri dengan satu kaki, melempar bola dan melakukan lompatan lebar. Hal ini dapat menciptakan perkembangan anak lebih optimal.

3. Perkembangan motorik halus Setelah dilakukan tabulasi dari hasil observasi didapat sebagian besar responden dengan perkembangan motorik halusnya dikatakan lebih/ advanced sebanyak 4 orang $(18,2 \%)$, normal sebanyak 16 orang $(71,7 \%)$ dan delay 2 orang $(9,1 \%)$.

Motorik halus adalah gerakan yang menggunakan otot-otot halus atau sebagian anggota tubuh tertentu, yang dipengaruhi oleh kesempatan untuk belajar dan berlatih. Misalnya, kemampuan memindahkan benda dari 
tangan, mencoret-coret, menyusun balok, menggunting, menulis dan sebagainya. Menurut Hidayat (2007), perkembangan motorik kasar menurut lembar observasi DDST anak usia 3-4 tahun diantaranya : mengikuti membuat kotak, menggambar orang 3 bagian, mengikuti, membuat + , membedakan garis lebih panjang (3 dari 4 atau 5 dari $6)$, meniru jembatan, menara dari 6 kubus dan mengikuti membuat lingkaran. Perkembangan motorik halus pada masa ini anak telah mampu mengkoordinasikan gerakan visual motorik, seperti mengkoordinasikan gerakan mata dengan tangan, lengan dan tubuh secara bersamaan antara lain dapat dilihat pada waktu anak menulis atau menggambar.

Dari hasil observasi yang dilakukan peneliti, perkembangan motorik halus yang dicapai anak diantaranya seperti mengikuti membat kotak, menggambar orang dengan 3 bagian, mengikiti membuat + , membedakan garis lebih panjang dan membuat garis lingkaran. Sedangkan yang masih belum dicapai yaitu cara membuat menara kubus karena anak tersebut belum bisa menata bentuk kubus untuk disusun menjadi menara. Dengan demikian anak-anak harus lebih sering dilatih dan diperhatikan perkembangan motorik halusnya, karena kemampuan tersebut sangat penting bagi anak untuk lebih terampil dan kreatif. Anak yang perkembangan motorik halusnya normal bahkan lebih/ advanced, anak itu akan merasa senang dan percaya diri bahwa dirinya bisa untuk melakukan motorik halus seperti menggambar dan melukis. Sedangkan anak yang perkembangan motorik halusnya mengalami keterlambatan atau delay dan caution pada anak disebabkan karena faktor ketidaktahuan anak dengan apa yang harus dilakukan. Perkembangan motorik ini juga dipengaruhi oleh beberapa faktor yang diantaranya ialah faktor lingkungan, faktor gizi dan pola pengasuhan. Faktorfaktor tersebut sangat berpengaruh dalam menstimulasi perkembangan motorik anak karena dengan gizi yang baik, lingkungan yang merangsang perkembangan anak, peran aktif orang tua dan pola pengasuhan yang tepat akan 
membuat perkembangan anak menjadi lebih sempurna.

Keterampilan anak pada aspek perkembangan motorik halus perlu dilatih, hal ini dapat dilakukan dengan melatih keterampilan anak dengan belajar menulis, menggunakan alat tulis dan menggambar. Dengan sering melatih anak dalam perkembangan motorik halus ini dapat menciptakan perkembangan anak yang lebih baik.

4. Hubungan pola asuh dalam menstimulasi perkembangan motorik kasar anak usia pra sekolah 3-4 tahun.

Setelah dilakukan tabulasi dari hasil observasi didapat sebagian besar responden yang menerapkan pola asuh authoritative dengan perkembangan motorik kasarnya dikatakan lebih/ advanced sebanyak 6 orang $(30,0 \%)$, normal sebanyak 14 orang $(70,0 \%)$ dari 20 responden. Sedangkan orang tua yang menerapkan pola asuh indulgent dengan perkembangan motorik kasar dikatakan delay sebanyak 2 orang $(100 \%)$ dari 2 responden.

Dari hasil analisa korelasi uji Chi - Square didapatkan bahwa ada hubungan pola asuh orang tua dalam menstimulasi perkembangan motorik kasar anak usia pra sekolah 3-4 tahun. Hal ini terbukti dari hasil perhitungan diperoleh hasil nilai Chi - Square didapat hasil $\rho<0,05$ yaitu $=22.000$ dengan signifikan 0,000 yang artinya $\mathrm{H}_{0}$ ditolak, berarti ada hubungan antara variabel. Jadi, Jika anak-anak dibesarkan dan diasuh dengan pola asuh yang authoritative, niscaya dapat tumbuh dan berkembang dengan baik. Seluruh potensi yang dimiliki anak dapat dikembangkan secara optimal.

Menurut Dinarti, (2010: 18) pola asuh authoritative mendorong anak untuk mandiri, tetapi orang tua harus tetap menetapkan batas dan kontrol. Orang tua biasanya bersikap hangat dan penuh welas asih kepada anak, bisa menerima alasan dari semua tindakan anak, mendukung tindakan anak yang konstruktif. Pola asuh bertujuan untuk mempertahankan kehidupan fisik anak dan meningkatkan kesehatannya memfasilitasi anak untuk mengembangkan kemampuan sejalan dengan tahapan perkembangan dan mendorong peningkatan kemampuan berperilaku sesuai dengan nilai agama dan budaya yang diyakininya. 
Dengan demikian pola asuh orang tua authoritative yang perkembangan motorik kasar yang dicapai anak akan normal bahkan lebih/ advanced karena anak diberi kesempatan untuk berlatih dan belajar untuk menggerakkan anggota tubuhnya sesuai dengan kemampuan anak. Sedangkan pola asuh indulgent didapat perkembangan motorik kasar anak yang dicapai anak yaitu delay karena anak tesebut masih merasa takut, tidak mau dan harus dibantu untuk melakukan gerakan tersebut. Perkembangan motorik yang abnormal dapat disebabkan karena kurangnya kesempatan untuk berlatih menggunakan anggota tubuhnya, adanya perlindungan yang berlebihan. Agar keluarga atau orang tua mampu melakukan fungsinya dengan baik maka orang tua perlu memahami tingkat perkembangan anak, menilai pertumbuhan dan perkembangan anak serta mempunyai motivasi yang kuat untuk memajukan tumbuh kembang anaknya dengan cara memberi pola pengasuhan yang baik terhadap anak.

Kemampuan anak pada aspek motorik perlu dilatih agar dapat berkembang dengan baik. Orang tua harus mengenali dan mendeteksi sejak kecil kelebihan dan kekurangan perkembangan motorik pada anak. Jika terdapat kekurangan dalam perkembangan motorik lainnya harus diberikan latihan sejak dini agar keterlambatan tersebut dapat diminimalkan. Hal ini dapat dilakukan dengan dorongan kegiatan khusus dengan melatih kemampuan gerakan otot besar anak untuk perkembangan anak yang lebih optimal.

5. Hubungan pola asuh orang tua dalam menstimulasi perkembangan motorik halus anak usia pra sekolah 3-4 tahun

Setelah dilakukan tabulasi dari hasil observasi didapat sebagian besar responden yang menerapkan pola asuh orang tua dengan perkembangan motorik halusnya dikatakan lebih/ advanced sebanyak 4 orang (20\%), normal 16 orang $(80,0 \%)$ dari 20 responden. Sedangkan orang tua yang menerapkan pola asuh indulgent dengan perkembangan motorik halus yaitu delay sebanyak 2 orang (100\%) dari 2 responden.

Dari hasil analisa korelasi uji Chi - Square didapatkan 
bahwa ada hubungan pola asuh orang tua dalam menstimulasi perkembangan motorik kasar anak usia pra sekolah 3-4 tahun. Hal ini terbukti dari hasil perhitungan diperoleh hasil nilai Chi - Square didapat hasil $\rho<0,05$ yaitu $=22.000$ dengan signifikan 0,000 yang artinya $\mathrm{H}_{0}$ ditolak, berarti ada hubungan antara variabel. Jadi, Jika anak-anak dibesarkan dan diasuh dengan pola asuh yang authoritative, niscaya dapat tumbuh dan berkembang dengan baik. Seluruh potensi yang dimiliki anak dapat dikembangkan secara optimal.

Menurut Dinarti, (2010: 18) pola asuh authoritative mendorong anak untuk mandiri, tetapi orang tua harus tetap menetapkan batas dan kontrol. Orang tua biasanya bersikap hangat dan penuh welas asih kepada anak, bisa menerima alasan dari semua tindakan anak, mendukung tindakan anak yang konstruktif.

Dengan demikian pola asuh orang tua authoritative yang perkembangan motorik halus yang dicapai anak akan normal bahkan lebih/ advanced karena anak diberi kesempatan untuk berlatih dan belajar untuk terampil dan lebih kreatif sesuai dengan kemampuan anak. Sedangkan pola asuh indulgent didapat perkembangan motorik halus anak yang dicapai anak yaitu delay, karena anak tesebut masih merasa belum bisa dan ragu-ragu dalam melakukan gerakan halus seperti menggambar. Perkembangan motorik yang abnormal dapat disebabkan karena kurangnya kesempatan anak untuk berlatih. Agar keluarga atau orang tua mampu melakukan fungsinya dengan baik maka orang tua perlu memahami tingkat perkembangan anak, menilai pertumbuhan dan perkembangan anak serta mempunyai motivasi yang kuat untuk memajukan tumbuh kembang anaknya dengan cara memberi pola pengasuhan yang baik terhadap anak.

Keterampilan anak pada aspek motorik perlu dilatih agar dapat berkembang dengan baik. Jika terdapat kekurangan dalam perkembangan motorik lainnya harus diberikan latihan sejak dini agar keterlambatan tersebut dapat diminimalkan. Hal ini dapat dilakukan dengan dorongan kegiatan khusus dengan melatih keterampilan anak untuk menciptakan 
perkembangan anak yang lebih optimal.

\section{Simpulan}

Pola asuh yang diterapkan pada penelitian, orang tua rata-rata menggunakan pola asuh authoritative. Sehingga pola asuh yang dilakuakan oleh orangtua dalam menstimulasi perkembangan motorik kasar anak usia pra sekolah 3-4 tahun di PAUD AL-Firdaus Bahrul 'Ulum Tambakberas Jombang sebagian responden yang menerapkan pola asuh authoritative dengan perkembangan motorik kasar yang normal bahkan advanced. Sedangkan sebagian responden menerapkan pola asuh indulgent dengan perkembangan motorik kasar dikatakan delay dan orang tua dalam menstimulasi perkembangan motorik halus anak usia pra sekolah 3-4 tahun di PAUD AL-Firdaus Bahrul 'Ulum Tambakberas Jombang sebagian responden yang menerapkan pola asuh authoritative perkembangan dengan halusnya dikatakan normal bahkan lebih/ advanced.
Sedangkan responden yang menerapkan pola asuh indulgent dengan perkembangan motorik halus dikatakan delay.

\section{Daftar Pustaka}

Arikunto, Suharsimi. 2002. Prosedur Penelitian Suatu Pendekatan Praktik. Jakarta: Rineka Cipta.

Dinarti, Desy, 2010. 145 Question \& Answers SMART Parenting menjadi Orang Tua Pintar Agar Anak Sukses. Yogyakarta: SIGMA.

Hidayat, Alimul. Aziz. 2008. Asuhan Neonatus Bayi dan Balita. Jakarta: EGC. 2008.

Pengantar Ilmu

Kesehatan Anak.

Jakarta: Salemba

Medika. . 2007.

Riset Keperawatan dan Teknik Penulisan Ilmiah. Jakarta: Salemba Medika.

Kartono, Kartini, 2007. Psikologi Anak (Psikologi 
perkembangan).

Bandung: Mandar maju.

Kristiyanasari, Weni \& Jitowiyono, Sugeng, 2010. Asuhan

Keperawatan

Neonatus \& Anak. Yogyakarta:

Nuhamedika.

Munir, Zainal. 2017.

"Analisis Pengaruh

Pendidikan, Pendapatan

Dan Pekerjaan Terhadap

Motivasi Orangtua

Dalam Kualitas

Perawatan Anak Dengan

HIV/AIDS WJK

Kab.Probolinggo."

Universitas

Muhammadiyah Jakarta. - 2018. Artikel.Pdf.

Surabaya.

(Munir 2017)(Munir 2018)

Notoatmodjo, Soekidjo. 2005.

Metodologi Penelitian

Kesehatan. Jakarta:

Rineka Cipta.

Nursalam. 2003. Konsep dan

Penerapan

Metodologi Penelitian

Ilmu Keperawatan.

Jakarta: Salemba

Medika.

Soejatmiko. 2009. Cara

Praktis Membentuk
Anak Sehat, Tumbuh

Kembang Optimal,

Kreatif dan Cerdas

Multipel. Jakarta:

Kompas Media

Nusantara.

Soedjatmiko. 2009. Materi

prsentasi pada

'Pelatihan Program

Kesehatan Balita Bagi

Penanggung Jawab

Program Kesehatan

Anak'. Stimulasi,

Deteksi dan Intervensi

Dini Gangguan

Tumbuh Kembang

Balita. Bogor.

Supartini, Yupi. 2002. Buku

Ajar Konsep Dasar

Keperawatan Anak.

Jakarta: EGC.

Soetjiningsih. 2003.

Perkembangan Anak

dan

Permasalahannya.

Jakarta: EGC.

Royhanati, Isy. 2003. Askeb

Neonatus, Bayi dan

Balita/ DDST. Jakarta:

EGC. 